\title{
Field efficacy of Exserohilum prolatum-a potential mycoherbicide for biological control of itchgrass (Rottboellia cochinchinensis)
}

\begin{abstract}
The experiments were conducted to evaluate the potential of the Exserohilum prolatum as a mycoherbicide for the itchgrass (Rottboellia cochinchinensis) control under natural conditions in two field experiments in a non crop situation and in association with a maize crop. Three doses were (single, double and triple) applied to the main plots with 2 week intervals. The sub-plot treatments were distilled water solution (check), the Exserohilum prolatum conidial concentration of 2x107, 2x108 and 2x109 conidial mL-1 or glyphosate (N(phosphonomethyl) glycine) herbicide as control check. Disease severity was rated at 5 day intervals after application and the area under disease progress curve (AUDPC) was calculated for each treatment. The above ground parts of the itchgrass and maize were recorded at the end of the experiment. The results showed that application frequency and inoculum concentration greatly influence the itchgrass control. Significantly higher percentage control of the itchgrass were recorded from triple application frequencies (90.4\%) compared to single (62.4\%) and double (70.4\%) applications. Within the three frequencies of application, increasing inoculum concentration increased the itchgrass control from between 53 to $90.4 \%$ compared to untreated check. The results indicate that the E. prolatum has a good potential as a biocontrol agent for the itchgrass.
\end{abstract}

Keyword: Bioherbicide, fungi, Exserohilum prolatum, the itchgrass (Rottoboellia cochinchinensis), maize, weed control 